\title{
The Relations of Self-reported Aggression to Alexithymia, Depression and Anxiety after Traumatic Brain Injury
}

\author{
Dawn Neumann, $\mathrm{PhD}$ \\ Assistant Research Professor \\ Indiana University School of Medicine, Department of Physical Medicine and Rehabilitation \\ Rehabilitation Hospital of Indiana \\ 4141 Shore Drive \\ Indianapolis, IN 46254 \\ Email: dmneuman@iupui.edu \\ Phone: 317-329-2188 \\ Corresponding author \\ James F. Malec, PhD \\ Professor and Research Director, Indiana University School of Medicine, Department of Physical \\ Medicine and Rehabilitation \\ Rehabilitation Hospital of Indiana \\ Indianapolis, IN \\ Flora M. Hammond, MD \\ Professor and Department Chair, Indiana University School of Medicine, Department of Physical \\ Medicine and Rehabilitation \\ Chief of Medical Affairs, Rehabilitation Hospital of Indiana \\ Indianapolis, IN
}

This research was funded by the National Institute on Disability, Independent Living, and Rehabilitation Research (NIDILRR) Switzer Research Fellowships Program Priority (CFDA No. 84.133F-1); the Indiana Spinal Cord and Brain Injury Research Fund; and the Indiana University Brain Rehabilitation, Advanced Imaging, and Neuroscience (BRAIN) Signature Center Initiative.

Conflicts of interest: Dr. Dawn Neumann is a small business owner that currently receives federal grant funding from the National Institutes of Health, NICHD STTR (grant \# 1R41HD077967-01A1), to develop and investigate an intervention related to concepts discussed in this manuscript. For the remaining authors, no other conflicts of interest are declared.

Reprint requests to Dawn Neumann, $\mathrm{PhD}$

Number of Words: (4500 max)

Key Words: Brain Injury, Emotion, Aggression, Depression, Anxiety, Alexithymia 


\begin{abstract}
Objectives: To compare self-reported aggression in people with and without traumatic brain injury (TBI), and examine the relations of aggression to alexithymia (poor emotional insight), depression and anxiety.
\end{abstract}

Setting: Rehabilitation hospital.

Participants: Forty-six adults with moderate to severe TBI who were at least three months postinjury; 49 healthy controls (HC); groups were frequency matched for age and gender.

Design: Cross-sectional study using a quasi-experimental design.

Main Measures: Aggression (Buss Perry Aggression Questionnaire); alexithymia (Toronto Alexithymia Scale-20); depression (Patient Health Questionnaire 9); and trait anxiety (State Trait Anxiety Inventory).

Results: Participants with TBI had significantly higher aggression scores than did HC. For participants with TBI, 34.2\% of the adjusted variance of aggression was significantly explained by alexithymia, depression and anxiety; alexithymia accounted for the largest unique portion of the variance in this model (16.2\%). Alexithymia, depression, and anxiety explained $46 \%$ of the adjusted variance of aggression in $\mathrm{HC}$; in contrast to participants with TBI, depression was the largest unique contributor to aggression (15.9\%).

Conclusion: This was the first empirical study showing that poor emotional insight (alexithymia) significantly contributes to aggression after TBI. This relation, and the potential clinical implications it may have for the treatment of aggression, warrants further investigation. 
It is widely acknowledged that problems with aggression are quite common after traumatic brain injury (TBI) ${ }^{1}$, with studies documenting aggression rates between $12 \%$ and $45 \%{ }^{2-6}$. While the prevalence of post-TBI aggression compared to that of healthy controls has been less studied, findings from two studies suggest that it is more pervasive in the TBI population. One study compared people with TBI in the acute stage to healthy controls, and found aggression to be present in three times more of those with TBI (33.7\%) than those without (11.5\%). ${ }^{7}$ Somewhat similar results were reported in another study that compared people who were in the chronic stages of TBI ( $\geq 6$ months post-injury) to people with chronic spinal cord injuries. High average to very high verbal aggression was found in 37.5\% of participants with TBI compared to $19 \%$ of people with spinal cord injury. ${ }^{4}$

Aggression is often associated with a variety of problems and negative outcomes after TBI. Aggression can interfere with therapy participation, thwart rehabilitation progress, and even be a barrier for acceptance into rehabilitation programs; in extreme cases, it has prevented people from returning to their pre-injury homes. ${ }^{8-11}$ In terms of employment, aggressive behaviors have been associated with more firings, less time employed ${ }^{12}$, and reduced employment integrity. ${ }^{13}$ In addition, problems with aggression not only affect the survivor with TBI, but also have a resounding impact on family and friends of the person with TBI. Relationships often become strained, the family frequently becomes socially isolated, and there is a reported increase in caregiver burden and a decrease in quality of life. ${ }^{14-}$ 20

Several studies have investigated risk factors and correlates of aggression in the TBI population. Studies that have focused on post-acute, long-term aggression after TBI (>3 months post-TBI) found aggression to be associated with depression; cognition (i.e., diminished verbal memory, visuo-perceptual skills and executive-attention functioning); social desirability; younger age at injury; alcohol and substance abuse; socioeconomic status; and pre-injury factors such as mood disorders, premorbid 
aggression, and low IQ. ${ }^{1,2,7,21}$ While the majority of studies have not detected a correlation with injury severity, aggression has been shown to be associated with diffuse brain injuries and injuries that involved frontal lobe damage. ${ }^{1}$

Understanding the risk factors associated with aggression is critical to developing treatment approaches aimed at mitigating factors likely to contribute to aggression. For instance, given the associations of impaired cognition and depression with aggression, various programs for aggression have typically used a combination of cognitive behavioral therapy (CBT) to alter maladaptive thoughts (which are believed to contribute to depressed mood and anger), in conjunction with training to improve problem-solving skills. ${ }^{8,22-24}$ Furthermore, medications for depression and cognition have also been used as an indirect approach for reducing aggression. ${ }^{25,26}$

The purpose of the current study was to investigate the correlation of a potential risk factor for self-reported problems with aggression that has been overlooked to date. We propose that aggressive behavior may be related to alexithymia - a disorder characterized by poor emotional insight - which would be a barrier to emotional self-regulation. Alexithymia is a multidimensional psychological construct introduced in 1970 by Nemiah and Sifneos (1970). ${ }^{27}$ Alexithymia is characterized not only by an inability to detect emotions in oneself, but also difficulty describing emotions, trouble differentiating emotions, poor interoceptive awareness, and problems associating physical sensations with emotions. ${ }^{28}$ People with alexithymia are often externally-oriented thinkers, meaning that they have a tendency to focus on concrete and factual information as opposed to feelings about situations and events. ${ }^{28}$ Although alexithymia can be a primary condition that results from one’s upbringing (e.g. social and cultural norms regarding emotions), it also can develop as a secondary condition due to a traumatic event (e.g. rape; medical condition), or from damage to the brain structures involving emotional processing. ${ }^{29}$ 
Alexithymia is quite common after TBI, with studies reporting a range between 30 and $61 \% .^{30-32}$, in contrast to approximately $10 \%$ of the general population. ${ }^{33}$ It is suspected that the elevated prevalence in the TBI population has to do with damage to the complex network of brain structures involved in emotion processing. In non-TBI populations, alexithymia has been associated with depression, anxiety, anger, poor recognition of others' emotion, lack of empathy, poor coping skills, and substance abuse. ${ }^{34-}$ ${ }^{42}$ While not studied quite as extensively as it has been in uninjured populations, evidence suggests that alexithymia has similar associations after TBI (i.e., poor recognition of others' emotions, depression, anxiety, avoidance coping, and low empathy). ${ }^{30-32,43-45}$ Also, it has been found to be associated with poor relationship quality and reduced quality of life. ${ }^{46}$ These studies did not find a significant association with injury severity or location. ${ }^{44}$ To date, no published studies have investigated the relation between alexithymia and aggression after TBI.

The aims of this study were to examine differences in self-reported aggression between people with and without TBI and to determine the relations of aggression with alexithymia, depression and anxiety. For the purposes of this study, aggression refers to subjective endorsements of aggressive acts (physical or verbal behavior), angry feelings and hostile thoughts as indicated by our main outcome measure, the Buss Perry Aggression Questionnaire. ${ }^{47}$ Depression and anxiety were included in this study since they are mood disorders that have previously been associated with aggression, and thus were added to obtain a more comprehensive understanding of the emotional factors contributing to aggression. It was hypothesized that participants with TBI would report significantly more aggression than healthy controls. Furthermore, we anticipated that aggression would be significantly correlated with alexithymia, depression, and anxiety, and that together, these three variables would account for a significant amount of aggression variance. 


\section{METHODS}

\section{Participants}

We recruited a sample of 46 participants with moderate to severe TBI and 49 healthy controls who were age and gender frequency matched with the TBI sample. This study was approved by the ethics review board of the participating institution, and all interested participants provided consent before participating in the study. Participants with TBI were recruited through letters sent to (current and former) patients of a local rehabilitation hospital, and flyers were posted in the hospital's outpatient clinic and distributed through local brain injury support groups. Healthy controls were recruited from local research study advertisements (e.g. University website; Craigslist). Recruitment materials specifically stated that we needed people with and without anger problems to better understand anger after brain injury.

All participants were between 18 and 75 years old. Consistent with the inclusion criteria of the study, participants with TBI had sustained a moderate to severe TBI ${ }^{48}$ at least three months prior to their study participation. All participants with TBI met one of the following injury severity criteria: Glasgow Coma Scale score $<13$ at the time of injury, post-traumatic amnesia $\geq 24$ hours, loss of consciousness $\geq 30$ minutes, or abnormal neuroimaging results consistent with moderate to severe brain injury. This information was initially obtained via self or family report for initial screening and was later confirmed via patient medical records for $83 \%$ of the participants; medical records were unavailable for the remainder. Participants with TBI were excluded if they had a pre-morbid acquired brain injury (e.g. stroke; anoxia), neurological disorder (e.g. autism; Alzheimer’s Disease), or major psychiatric disorder (e.g. schizophrenia, bipolar disorder). Healthy control participants underwent a screening interview and were excluded if they had ever been diagnosed with a neurological injury or disorder (e.g. acquired brain 
injury, stroke, Alzheimer’s), developmental disorder, or major psychiatric disorder (e.g. schizophrenia, bipolar disorder).

Please refer to Table 1 for participant demographics and injury characteristics for participants with TBI.

-[INSERT TABLE 1]

\section{Measures}

Buss-Perry Aggression Questionnaire (AQ) ${ }^{47}$ : The AQ is a 34-item subjective questionnaire that uses a 5-point Likert scale to evaluate overall aggression and four aggression subconstructs: anger, hostile thoughts, and physical and verbal aggression. Total raw scores range from 34-170. These scores were converted to t-scores based on age and gender norms. T scores of $\geq 56$ indicate high average to very high aggression. The AQ has been shown to have good test-retest reliability (.72-.80) and internal consistency (.76-.94). ${ }^{47}$ This standardized measure has been widely used in many populations, including TBI. ${ }^{4,49-53}$

Toronto Alexithymia Scale (TAS-20) $)^{28,54}$ : The TAS-20 is a 20-item questionnaire that measures total alexithymia, and three subconstructs: difficulty identifying feelings (emotional self-awareness), difficulty describing feelings, and externally-oriented thinking. Scores range between 20-100; scores of 51 or less indicate low alexithymia; scores of 61 and higher indicate high alexithymia; scores in between indicate moderate alexithymia. The TAS-20 is the most widely used assessment instrument for alexithymia and has been shown to have good internal consistency, validity, and test-retest reliability. ${ }^{28,54}$

Patient Health Questionnaire (PHQ-9) ${ }^{55}$ : The PHQ-9 is a 9 item inventory used to measure depression on a Likert scale that ranges from 0-3. Participants identify the frequency with which they have experienced specified problems during the past two weeks. Problems refer to loss of interest, 
feeling down, sleep, fatigue, poor appetite, feeling bad about oneself, difficulty concentrating, moving slower, and thoughts of suicide. The total score is used to determine depression severity which is further divided into the following categories: Severe (20-27); moderately severe (15-19); moderate (10-15); mild; (5-9) and none (0-4). Prior studies indicate that the PHQ-9 has good validity in the general population as well as in people with TBI, is sensitive to the presence of depression, and has good reliability. ${ }^{56,57}$

State Trait Anxiety Inventory $(S T A I)^{58}$ : The STAI is a self-report measure of anxiety as a transient state and a persisting trait (20 items each). For the State Anxiety scale, participants respond with respect to how they feel in that moment, whereas the Trait Anxiety scale asks participants to report how they generally feel. Both use a 4 point Likert scale and scores range from 20-80 for each. Higher scores indicate greater trait or state anxiety. Raw scores are converted to standard scores based on age and gender. For the purposes of this study, we only report participants' trait anxiety scores. The STAI has been shown to have concurrent validity with the Taylor Manifest Anxiety Scale, the IPAT Anxiety Scale, and the Multiple Affect Adjective Check List ( $r=.80, .75$, and .52, respectively). ${ }^{59}$

\section{Procedures}

Interested participants were prescreened to determine if they met the general study criteria; this usually occurred over the phone, but sometimes in person if they found out about the study while at the hospital where the study was being conducted. Eligible participants with TBI came to the rehabilitation hospital for the consent process and subsequent testing, provided they gave consent. A research assistant read all of the questions for each measure and recorded the participants' responses. For each measure, the appropriate response options were visible for the participant to refer to in making their selection. Interested and eligible healthy controls were usually mailed a testing packet, or given a packet in person that they returned to us upon completion. Healthy controls were not required to complete testing in 
person because, in contrast to participants with TBI, there was no concern that they would need assistance to accurately complete and return the assessment forms. All participants completed a Demographic and Medical History Questionnaire, followed by the AQ (aggression), TAS-20 (alexithymia), PHQ-9 (depression), and the STAI (anxiety).

\section{Data Analysis}

SPSS 23 (SPSS Inc, Chicago, Illinois) was used for all analyses. Descriptive statistics, including means, standard deviations, and percentages were calculated for participant characteristics and main outcomes. Scores from the Buss Perry Aggression Questionnaire, and trait scores from the State Trait Anxiety Inventory were converted to t scores and used for all analyses. Two-tailed independent t-tests were calculated to compare group differences for aggression, alexithymia, depression, and trait anxiety. The Holm-Bonferroni ${ }^{60}$ method was used to adjust for multiple comparisons. $d_{\text {Cohen }}$ was calculated to determine effect sizes between groups. Chi Square analyses were performed to compare group difference for sex and the frequency of high-average to high aggression ( $\geq 56 \mathrm{t}$-scores). For the TBI group, Spearman Rho correlations were calculated to examine the relations of aggression with injury characteristics (PTA, LOC, and months post-injury) and also to examine the relations of aggression with alexithymia, depression and trait anxiety for both groups. Finally, multiple linear regressions (Enter method) were calculated separately for TBI and Control groups to determine the amount of aggression variance accounted for by alexithymia, depression, and anxiety combined. Analyses were separated by group to gain a more precise understanding of the relations among these variables specifically in the TBI population, as well as to observe how these relations may differ between people with and without TBI. Unless otherwise stated, an $\alpha$ level of .05 was set for all analyses.

\section{RESULTS}

\section{Group Demographic Comparisons}


Participants with TBI and healthy controls did not significantly differ in age $(\mathrm{t}=-.262, \mathrm{p}=.794)$, $\operatorname{sex}\left(\chi^{2}=.000, \mathrm{p}=.996\right)$, or years of education $(\mathrm{t}=-1.899, \mathrm{p}=.061)$. Refer to Table 1 for descriptive statistics.

Association of aggression with injury-related characteristics and education

For the TBI group, Total Aggression scores on the Buss Perry Aggression Questionnaire were not significantly associated with self-reported posttraumatic amnesia duration (rho=.120, p=.613; $n=20)$, medically documented GCS (rho=-.045, p=.818; $\mathrm{n}=29$ ), self-reported loss of consciousness days (rho=.328, $\mathrm{p}=.067 ; \mathrm{n}=32$ ), medically documented LOC days (rho=-.067, $\mathrm{p}=.786 ; \mathrm{n}=19$ ), or months postinjury (rho=-.155, p=.303). Aggression was not significantly associated with years of education in the TBI (rho=-.277, $\mathrm{p}=.063$ ) or Healthy Control (rho=.073, $\mathrm{p}=.622$ ) groups. Correlations were not calculated for gender and age with aggression since $\mathrm{T}$ scores were based on age and gender norms. Group Comparisons: Aggression, Alexithymia, Depression, and Anxiety

Participants with TBI had significantly higher total aggression, physical aggression, verbal aggression, anger, and hostility compared to healthy controls. See Table 2 for descriptive statistics, tscore results and effect sizes. After applying the Holm-Bonferroni Correction, all comparisons remained significant. High-average to high total aggression (T scores $\geq 56$ ) was found in $34.8 \%$ of participants with TBI in contrast to $14.3 \%$ of healthy controls, which was significantly different $\left(\chi^{2}=5.432, p=.020\right)$. When aggression subcategories were parsed out, significantly more participants with TBI had highaverage to high verbal aggression (41.3\% vs $\left.18.4 \% ; \chi^{2}=6.005, \mathrm{p}=.014\right)$, anger $(39.1 \%$ vs $20.4 \%$; $\chi^{2}=4.001, \mathrm{p}=.045$ ), and hostility (45.7\% vs 20.4\%; $\left.\chi^{2}=6.878, \mathrm{p}=.009\right)$. The number of participants who were classified as having high-average to high physical aggression did not significantly differ between groups (26.1\% vs $\left.14.3 \% ; \chi^{2}=2.065, \mathrm{p}=.151\right)$. 
Participants with TBI had significantly higher alexithymia, depression, and trait anxiety scores compared to Healthy Controls. Again, refer to Table 2 for descriptive statistics, t-score results and effect sizes. Because Levene’s test indicated unequal variances, these latter t-tests were conducted with appropriate modification.

-INSERT TABLE 2

Associations of Aggression with Alexithymia, Depression, and Anxiety: TBI group

Total aggression was significantly associated with total alexithymia (rho=.600, $<<.001$ ), depression (rho=.328, $\mathrm{p}=.026)$, and trait anxiety (rho=.400, $\mathrm{p}=.006)$. A standard multiple linear regression (using the Enter method) was calculated to determine if aggression variance was significantly explained by alexithymia, depression, and anxiety. Alexithymia, depression, and anxiety variables were entered simultaneously into the analyses since all had moderate individual correlations with aggression. Together, the 3 constructs significantly accounted for $34.2 \%$ of the adjusted aggression variance. Tolerance and variance inflation (VIF) scores indicated that multicollinearity was not a problem in this model.

Associations of Aggression with Alexithymia, Depression, and Anxiety: Healthy Controls

Total aggression was significantly associated with total alexithymia (rho=.388, $\mathrm{p}=.006$ ), depression (rho=.768, $\mathrm{p}<.001)$, and trait anxiety (rho=.622, $\mathrm{p}=.002)$. A standard multiple linear regression (using the Enter method) was calculated to determine if aggression variance was significantly explained by alexithymia, depression, and anxiety. Again, these variables were entered simultaneously into the regression model, accounting $\backslash$ for $46 \%$ of the adjusted aggression variance. Tolerance and VIF scores showed that multicollinearity was not a concern. 


\section{DISCUSSION}

Although aggression is a typical outcome after TBI, there is a dearth of studies that have empirically tested the widely accepted belief that aggression is more significant and common than in healthy controls. Our preliminary results provide empirical data to support these beliefs. First, our findings indicated that participants with TBI had higher total aggression, physical aggression, verbal aggression, anger, and hostility than did healthy controls. Furthermore, comparisons of aggression prevalence between our two participant groups revealed that a greater number of participants with TBI were classified as having high-average to high verbal aggression, anger, and hostility compared to healthy controls. These findings are consistent with a previous study conducted by Dyer et al. which showed that participants with chronic TBI $(n=24)$ had significantly higher levels of aggression compared to healthy controls $(n=24) .^{4}$

Another aim of this study was to investigate the relation of aggression with alexithymia, in addition to depression and anxiety. Alexithymia is a psychological construct that has been gaining more traction in the TBI literature over the last decade. Characterized by poor emotional self-awareness and difficulty describing emotions, it has been shown to be three to six times more common in persons with TBI compared to those without TBI. ${ }^{30,31}$ Although alexithymia has been associated with an array of other emotion dysregulation disorders in both the TBI and non-TBI populations ${ }^{31,37,43,44,61,62}$, this is the first published study to investigate its relation with aggression after TBI. Findings from this study showed that aggression was moderately to strongly associated with alexithymia, depression, and anxiety in both TBI and healthy control participants. These three variables explained $34.2 \%$ of the aggression variance for participants with TBI, and $45.7 \%$ of the variance for healthy controls. Moreover, the amount of unique variance that each variable contributed to the regression can be determined by squaring the part correlations found in Table 3. These correlations indicated that alexithymia accounted 
for the bulk of the variance for participants with TBI (16.2\%); in contrast, depression was the major contributor to the model for healthy controls (15.9\%). This suggests that factors that contribute to aggression differ between people with and without TBI. It is possible that depression played a stronger role than alexithymia in healthy controls because depression was more prevalent than alexithymia in this group. Although depression is quite common after TBI, it may be secondary to the alexithymia. ${ }^{63,64}$ This would explain why alexithymia made a larger contribution to the model than depression for the TBI group.

There are several theories as to why aggression would be associated with alexithymia. Emotional awareness and the ability to label emotions are thought to be critical to emotional and behavioral selfregulation. Persons who are unaware of their anger theoretically would not be able to make a conscious effort to alter or control the emotion (e.g. prevent it from escalating) that can be expressed by acts of aggression (e.g. yelling and cursing). This rationale suggests that persons with alexithymia would be at risk for problems with aggression and other emotion dysregulation disorders as is supported by studies in healthy controls ${ }^{34,61}$ as well as the findings from this study in persons with TBI.

Another possible explanation for the association between alexithymia and aggression concerns difficulty labeling emotions. Neuroimaging studies show that when participants identify (label) emotions (usually portrayed by facial expressions), the prefrontal cortex is engaged while activity in the amygdala is simultaneously reduced. ${ }^{65-68}$ In contrast, more activity is observed in the amygdala when participants view the facial expressions without labeling the emotions. ${ }^{65-68}$ From these findings, it has been inferred that the cognitive act of labeling emotions, which requires prefrontal activity, is a form of down regulating the implicit and automatic limbic response to an emotional stimulus; in other words, labeling emotions dampens the emotional response.

\section{Clinical Implications.}


Although replication with larger samples is always desirable, our results suggest that researchers and clinicians should examine the feasibility of treating alexithymia after TBI (e.g. improving emotional awareness and vocabulary to label their emotions). Treatments focusing on methods to increase participants' awareness and ability to label their emotions may enhance their ability to engage CBT strategies to regulate unpleasant, angry emotions before they escalate and drive their behavior. According to the labeling theory above, it is possible that the cognitive act of labeling emotions may help to reduce feelings of aggression. If alexithymia can be reduced in people with TBI, it would be clinically relevant to assess for alexithymia in patients who are aggressive and to evaluate the benefit of including an alexithymia treatment as part of a comprehensive treatment program for aggression after TBI (e.g. emotional awareness training plus CBT). Currently, a handful of emotion regulation / CBT models include some degree of emotional self-awareness training for participants with $\mathrm{TBI}^{22-24,69}$; however, it has never been the primary emphasis of the treatment. It is unclear how much time these programs spent on training emotional self-awareness and emotional vocabulary or if it effectively reduced alexithymia. If findings from the current study are replicated, there may be value in efforts to develop a better understanding of the contributions of the emotional awareness training in the current models to reduce alexithymia and overall aggression, or if a more elaborate program with a stronger alexithymia emphasis would be more effective.

There is promising evidence that alexithymia can improve with treatment. In one study, a six session manualized group therapy training program reduced alexithymia in a small sample of otherwise normal males who had alexithymia. ${ }^{70}$ Reductions in alexithymia were also observed in a case study of a patient who had had a stroke and subsequently underwent an intervention consisting of emotional vocabulary lessons and biofeedback to overcome his alexithymia. ${ }^{71}$ Although this second study was a 
single case study, it indicated that even after neurological damage, alexithymia is a condition that can potentially benefit from treatment.

\section{Limitations.}

All of our outcomes relied on self-report questionnaires. While accuracy of self-report can sometimes present a concern in the TBI population, Dyer et al compared self and other reported outcomes on the Buss Perry Aggression Questionnaire and found the reports to be relatively similar. ${ }^{4}$ In addition, because alexithymia is a measure of one's own emotional experience and understanding, it would not be valid to obtain this information from another person.

Another potential limitation of the study is the difference in how the data was collected between the two groups. As described in the Procedures section, participants with TBI completed the study during an in-person interview, while, a packet of questionnaires was mailed to the homes of participants without TBI and completed independently. While it is possible this difference can alter the way someone would respond, it would likely steer the results in the opposite direction from what was found. For instance, in-person interviews (in this case, those with our participants with TBI) may be more likely to cause under-reporting of aggression tendencies than cases in which the questionnaires were completed independently (in this case our healthy controls). Therefore, even though it may be considered a flaw that the data was collected differently for both groups, it is unlikely that it is contributing to the differences observed in our results.

The sample size, although adequate for planned analyses, is relatively small and of uncertain representativeness, potentially limiting generalizability. Moreover, the small sample size of this preliminary study precluded us from examining the association of aggression with other potential covariates (e.g. socio-economic status). Finally, medical records were not obtainable for all participants 
with TBI, meaning that we had to rely on self-report of certain factors for a small percentage of these individuals.

\section{CONCLUSION}

Chronic problems with aggression are a characteristic outcome after TBI. This study provided empirical evidence for the view that aggression is indeed more prevalent in people with TBI than healthy controls. Differences were mainly observed for verbal aggression, anger and hostility, whereas, the prevalence of more severe physical aggression appeared to be similar between the two groups. Treating aggression is challenging mainly because causative factors may be multiple and complex. Identifying factors that contribute to aggression promotes the likelihood of developing successful treatments with more robust effects. This study was the first to demonstrate a relation between aggression and alexithymia. It is possible that poor emotional awareness and difficulty labeling emotions may interfere with emotion regulation, and therefore contribute to increased levels of aggression after TBI. This novel discovery is worth further exploration and may play a vital role in how treatment for aggression is approached in the future. 


\begin{tabular}{|c|c|c|}
\hline Characteristic & $\begin{array}{c}\text { TBI }(\mathrm{n}=46) \\
\text { Mean (SD; range)/ } \\
\text { Frequency }(\%)\end{array}$ & $\begin{array}{l}\text { Healthy Controls }(\mathrm{n}=49) \\
\text { Mean (SD)/Frequency (\%) }\end{array}$ \\
\hline Age & $42.28(14.42 ; 20-67)$ & $43.04(13.75 ; 19-71)$ \\
\hline $\begin{array}{r}\text { Gender } \\
\text { Male }\end{array}$ & $67.4 \%$ & $67.3 \%$ \\
\hline $\begin{array}{rr}\text { Race/Ethnicity } & \\
& \text { Caucasian } \\
\text { Hispanic } \\
\text { Black }\end{array}$ & $\begin{array}{c}91.3 \% \\
4.3 \% \\
4.3 \% \\
\end{array}$ & $\begin{array}{c}71.4 \% \\
8.2 \% \\
18.4 \% \\
\end{array}$ \\
\hline Education (Years) & $14.78(2.55 ; 10-20)$ & 15.67 (1.89; 12-19) \\
\hline $\begin{array}{l}\text { Cause of Injury } \\
\text { Motor Vehicle Accident } \\
\text { Fall } \\
\text { Assault } \\
\text { Other } \\
\end{array}$ & $\begin{array}{c}58.7 \% \\
19.6 \% \\
2.2 \% \\
19.86 \%\end{array}$ & \\
\hline Months post-injury & 58.40 (61.32; 8-289) & \\
\hline GCS, Medical Records $(n=29)$ & $9.83(2.94 ; 3-15)$ & \\
\hline $\begin{array}{r}\text { LOC, days } \\
\text { Self-report }(n=34) \\
\text { Medical Records }(n=19)\end{array}$ & $\begin{array}{l}14.75(21.25 ; 0-90) \\
9.1053(6.05 ; 0-16)\end{array}$ & \\
\hline Self-report PTA, days $(n=21)$ & $26.63(39.50 ; 2-180)$ & \\
\hline $\begin{array}{l}\text { Abnormal neuroimaging } \\
\text { results ( } \mathrm{n}=38 \text { ) (yes) } \\
\text { e.g. (Hematoma, Hemorrhage, } \\
\text { Contusions, Diffuse Axonal } \\
\text { Injury) }\end{array}$ & $92 \%$ & \\
\hline
\end{tabular}




\begin{tabular}{|r|c|c|c|c|}
\hline \multicolumn{5}{|l|}{ Table 2. Group Comparisons } \\
\hline & $\begin{array}{c}\text { TBI } \\
\text { Mean (SD) }\end{array}$ & $\begin{array}{c}\text { Healthy Controls } \\
\text { Mean (SD) }\end{array}$ & $\begin{array}{c}\text { Group } \\
\text { Comparison }\end{array}$ & $\begin{array}{c}\text { Effect size } \\
\boldsymbol{d}_{\text {Cohen }}\end{array}$ \\
\hline Total AQ (T score) & $\begin{array}{c}52.00 \\
(10.372)\end{array}$ & $45.20(9.61)$ & $\mathrm{t}=3.258, \mathrm{p}=.002$ & .680 \\
\cline { 2 - 5 } \begin{tabular}{r} 
Physical Aggression (T) \\
Verbal Aggression (T) \\
Anger (T) \\
\cline { 2 - 5 } Hostility (T)
\end{tabular} & $50.89(8.64)$ & $46.41(7.64)$ & $\mathrm{t}=2.683, \mathrm{p}=.009$ & .549 \\
\cline { 2 - 5 } & $54.08(11.26)$ & $47.51(9.39)$ & $\mathrm{t}=2.534, \mathrm{p}=.013$ & .519 \\
\hline Alexithymia & $51.02(11.40)$ & $46.71(10.62)$ & $\mathrm{t}=2.801, \mathrm{p}=.006$ & .573 \\
\hline Depression & $8.87(14.79)$ & $33.96(12.15)$ & $\mathrm{t}=3.407, \mathrm{p}<.001$ & .699 \\
\hline Trait Anxiety T scores & $58.70(15.68)$ & $48.35(11.66)$ & $\mathrm{t}=3.633, \mathrm{p}<.001$ & .749 \\
\hline
\end{tabular}


Table 3. Predictors of aggression in people with TBI and Healthy Controls.

\begin{tabular}{|c|c|c|c|c|c|c|c|c|c|c|c|}
\hline 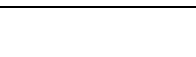 & $\mathbf{R}$ & $\mathbf{R}^{2}$ & Adjusted & $\mathbf{F}$ & Sig & Beta & t & Sig & Part & Colline & \\
\hline \multirow{2}{*}{$\begin{array}{l}\text { Total } \\
\text { Aggression } \\
\text { (TBI) } \\
\text { Alexithymia } \\
\text { Depression } \\
\text { Anxiety }\end{array}$} & \multirow[t]{2}{*}{.621} & \multirow[t]{2}{*}{.386} & \multirow[t]{2}{*}{.342} & \multirow[t]{2}{*}{8.79} & \multirow[t]{2}{*}{$<.001$} & \multirow[b]{2}{*}{$\begin{array}{l}.558 \\
.080 \\
.019\end{array}$} & \multirow[b]{2}{*}{$\begin{array}{l}3.33 \\
.437 \\
.093\end{array}$} & \multirow[b]{2}{*}{$\begin{array}{l}.002 \\
.665 \\
.926\end{array}$} & \multirow[b]{2}{*}{$\begin{array}{l}.402 \\
.053 \\
.011\end{array}$} & Tolerance & VIF \\
\hline & & & & & & & & & & $\begin{array}{l}.520 \\
.440 \\
.345\end{array}$ & $\begin{array}{l}1.923 \\
2.272 \\
2.901\end{array}$ \\
\hline $\begin{array}{l}\text { Total } \\
\text { Aggression } \\
\text { (HC) } \\
\text { Alexithymia } \\
\text { Depression } \\
\text { Anxiety }\end{array}$ & .703 & .494 & .460 & 14.64 & $<.001$ & $\begin{array}{r}.212 \\
.605 \\
-.002\end{array}$ & $\begin{array}{c}1.55 \\
3.76 \\
-.011\end{array}$ & $\begin{array}{l}.129 \\
<.001 \\
.991\end{array}$ & $\begin{array}{r}.164 \\
.399 \\
-.001\end{array}$ & $\begin{array}{l}.595 \\
.435 \\
.306\end{array}$ & $\begin{array}{l}1.68 \\
2.30 \\
3.27\end{array}$ \\
\hline
\end{tabular}




\section{References}

1. Kim E, Lauterbach EC, Reeve A, et al. Neuropsychiatric Complications of Traumatic Brain Injury. The Journal of Neuropsychiatry and Clinical Neurosciences. 2007;19(2):106-127.

2. Baguley IJ, Cooper, J., and Felmingham, K. Aggressive behavior following traumatic brain injury How Common Is Common? Journal of Head Trauma Rehabilitation. 2006;21(1):45-56.

3. Draper K, Ponsford J, Schönberger M. Psychosocial and emotional outcomes 10 years following traumatic brain injury. The Journal of head trauma rehabilitation. 2007;22(5):278-287.

4. Dyer KFW, Bell R, McCann J, Rauch R. Aggression after traumatic brain injury: Analysing socially desirable responses and the nature of aggressive traits. Brain Injury. 2006;20(11):1163-1173.

5. Kilmer RP, Demakis GJ, Hammond FM, Grattan KE, Cook JR, Kornev AA. Use of the neuropsychiatric inventory in traumatic brain injury: A pilot investigation. Rehabilitation Psychology. 2006;51(3):232-238.

6. Neumann D, Malec JF, Hammond FM. The Association of Negative Attributions With Irritation and Anger After Brain Injury. Rehabilitation Psychology. In press, 2015.

7. Tateno A, Jorge RE, Robinson RG. Clinical correlates of aggressive behavior after traumatic brain injury. The Journal of neuropsychiatry and clinical neurosciences. 2003;15(2):155-160.

8. Alderman N. Contemporary approaches to the management of irritability and aggression following traumatic brain injury. Neuropsychological Rehabilitation. 2003;13(1):211-240.

9. Burke WH, Wesolowski MD, Lane I. A positive approach to the treatment of aggressive brain injured clients. International Journal of Rehabilitation Research. 1988;11(3):235.

10. Eames PE, Wood RL. Episodic disorders of behaviour and affect after acquired brain injury. Neuropsychological Rehabilitation. 2003;13(1):241-258.

11. Prigatano GP. Psychiatric aspects of head injury: Problem areas and suggested guidelines for research. 1987.

12. Sansone RA, Leung JS, Wiederman MW. Aggressive behavior and employment histories in patients from an internal medicine outpatient clinic. Comprehensive psychiatry. 2012.

13. Harris JA. The relationship between aggression and employment integrity. Journal of Business and Psychology. 1997;12(1):39-44.

14. Demark J, Gemeinhardt M. Anger and it s management for survivors of acquired brain injury. Brain Injury. 2002;16(2):91-108.

15. Felmingham KL, Baguley IJ, Crooks J. A comparison of acute and postdischarge predictors of employment 2 years after traumatic brain injury. Archives of Physical Medicine and Rehabilitation. 2001;82(4):435-439.

16. Khan F, Baguley IJ, Cameron ID. 4: Rehabilitation after traumatic brain injury. Medical Journal of Australia. 2003;178(6):290-297.

17. Lezak MD. Psychological implications of traumatic brain damage for the patient's family. Rehabilitation Psychology. 1987;31(4):241-250.

18. Lezak MD, O'Brien KP. Longitudinal study of emotional, social, and physical changes after traumatic brain injury. Journal of Learning Disabilities. 1988;21(8):456.

19. Oddy M, Coughlan T, Tyerman A, Jenkins D. Social-Adjustment after Closed Head-Injury - a Further Follow-up 7 Years after Injury. Journal of Neurology Neurosurgery and Psychiatry. 1985;48(6):564568.

20. Winkler D, Unsworth, C., and Sloan, S. Factors that lead to successful community integration following severe traumatic brain injury. Journal of Head Trauma Rehabilitation. 2006;21(1):8-21.

21. Wood RL, Liossi C, Wood L. The impact of head injury neurobehavioural sequelae on personal relationships: preliminary findings. Brain Inj. 2005;19(10):845-851. 
22. Hart T, Vaccaro MJ, Hays C, Maiuro RD. Anger self-management training for people with traumatic brain injury: a preliminary investigation. The Journal of head trauma rehabilitation.

2012;27(2):113-122.

23. Medd J, Tate RL. Evaluation of an anger management therapy programme following acquired brain injury: A preliminary study. Neuropsychological Rehabilitation. 2000;10(2):185-201.

24. Walker AJ, Nott MT, Doyle M, Onus M, McCarthy K, Baguley IJ. Effectiveness of a group anger management programme after severe traumatic brain injury. Brain Injury. 2010;24(3):517-524.

25. Hammond FM, Sherer M, Malec JF, et al. Amantadine Effect on Perceptions of Irritability after Traumatic Brain Injury: Results of the Amantadine Irritability Multisite Study. Journal of neurotrauma. 2015.

26. Warden DL, Gordon B, McAllister TW, et al. Guidelines for the pharmacologic treatment of neurobehavioral sequelae of traumatic brain injury. Journal of Neurotrauma. 2006;23(10):14681501.

27. Nemiah JC, Sifneos PE. Psychosomatic illness: a problem in communication. Psychotherapy and Psychosomatics. 1970;18(1-6):154-160.

28. Bagby RM, Parker JDA, Taylor GJ. The 20-Item Toronto-Alexithymia-Scale .1. Item Selection and Cross-Validation of the Factor Structure. Journal of Psychosomatic Research. 1994;38(1):23-32.

29. Messina A, Beadle J, Paradiso S. Towards a classification of alexithymia: primary, secondary and organic. Journal of Psychopathology. 2014;20:38-49.

30. Neumann D, Zupan B, Malec JF, Hammond F. Relationships between alexithymia, affect recognition, and empathy after traumatic brain injury. The Journal of Head Trauma Rehabilitation. 2014;29(1):E18-27.

31. Williams C, Wood RL. Alexithymia and emotional empathy following traumatic brain injury. Journal of Clinical and Experimental Neuropsychology. 2010;32(3):259-267.

32. Wood RL, Doughty C. Alexithymia and avoidance coping following traumatic brain injury. The Journal of head trauma rehabilitation. 2013;28(2):98-105.

33. Kokkonen P, Karvonen JT, Veijola J, et al. Prevalence and sociodemographic correlates of alexithymia in a population sample of young adults. Comprehensive psychiatry. 2001;42(6):471-476.

34. Berenbaum H, Irvin S. Alexithymia, anger, and interpersonal behavior. Psychotherapy and psychosomatics. 1996.

35. Besharat MA. Relationship of alexithymia with coping styles and interpersonal problems. ProcediaSocial and Behavioral Sciences. 2010;5:614-618.

36. Einspruch BC. Disorders of Affect Regulation: Alexithymia in Medical and Psychiatric Illness. JAMA: The Journal of the American Medical Association. 1998;279(7):555.

37. Honkalampi K, Hintikka J, Tanskanen A, Lehtonen J, Viinamäki H. Depression is strongly associated with alexithymia in the general population. Journal of psychosomatic research. 2000;48(1):99-104.

38. Jessimer M, Markham R. Alexithymia: a right hemisphere dysfunction specific to recognition of certain facial expressions? Brain and Cognition. 1997;34(2):246-258.

39. Kano M, Fukudo S, Gyoba J, et al. Specific brain processing of facial expressions in people with alexithymia: an H2150-PET study. Brain. 2003;126(6):1474.

40. Lane RD, Sechrest L, Reidel R, Weldon V, Kaszniak A, Schwartz GE. Impaired verbal and nonverbal emotion recognition in alexithymia. Psychosom Med. 1996;58(3):203-210.

41. Lane RD, Sechrest L, Riedel R, Shapiro DE, Kaszniak AW. Pervasive emotion recognition deficit common to alexithymia and the repressive coping style. Psychosom Med. 2000;62(4):492-501.

42. Velasco C, Fernández I, Páez D, Campos M. Perceived emotional intelligence, alexithymia, coping and emotional regulation. Psicothema. 2006;18(Suplemento):89-94.

43. Henry J, Phillips L, Crawford J, Theorodou G, Summers F. Cognitive and psychosocial correlates of alexithymia following traumatic brain injury. Neuropsychologia. 2006;44:62-72. 
44. Koponen S, Taiminen T, Honkalampi K, et al. Alexithymia after traumatic brain injury: its relation to magnetic resonance imaging findings and psychiatric disorders. Psychosomatic Medicine. 2005;67(5):807-812.

45. McDonald S, Rosenfeld J, Henry JD, Togher L, Tate R, Bornhofen C. Emotion perception and Alexithymia in people with severe traumatic brain injury: One disorder or two?: A preliminary investigation. Brain Impairment. 2011;12(3):165.

46. Williams C, Wood RL. The impact of alexithymia on relationship quality and satisfaction following traumatic brain injury. The Journal of head trauma rehabilitation. 2013;28(5):E21-E30.

47. Buss AH, Perry M. The aggression questionnaire. Journal of Personality and Social Psychology. 1992;63(3):452-459.

48. Malec JF, Brown AW, Leibson CL, et al. The Mayo classification system for traumatic brain injury severity. Journal of Neurotrauma. 2007;24(9):1417-1424.

49. Greve KW, Sherwin E, Stanford MS, Mathias C, Love J, Ramzinski P. Personality and neurocognitive correlates of impulsive aggression in long-term survivors of severe traumatic brain injury. Brain Injury. 2001;15(3):255-262.

50. Holtzworth-Munroe A, Rehman U, Herron K. General and spouse-specific anger and hostility in subtypes of maritally violent men and nonviolent men*. Behavior Therapy. 2000;31(4):603-630.

51. Hoptman MJ, D'Angelo D, Catalano D, et al. Amygdalofrontal functional disconnectivity and aggression in schizophrenia. Schizophrenia Bulletin. 2009.

52. Palmer EJ, Thakordas V. Relationship between bullying and scores on the Buss-Perry Aggression Questionnaire among imprisoned male offenders. Aggressive Behavior. 2005;31(1):56-66.

53. Neumann D, Malec JF, Hammond FM. The association of negative attributions with irritation and anger after brain injury. Rehabilitation psychology. 2015;60(2):155.

54. Bagby RM, Taylor GJ, Parker JDA. The 20-Item Toronto-Alexithymia-Scale .2. Convergent, Discriminant, and Concurrent Validity. Journal of Psychosomatic Research. 1994;38(1):33-40.

55. Beck AT, Steer, R. A., and Brown, G. K., ed The Beck Depression Inventory-Second Edition. . San Antonio, TX: The Psychological Corporation; 1996.

56. Fann JR, Bombardier CH, Dikmen S, et al. Validity of the Patient Health Questionnaire-9 in assessing depression following traumatic brain injury. The Journal of Head Trauma Rehabilitation. 2005;20(6):501-511.

57. Kroenke K, Spitzer RL, Williams JBW. The PHQ-9. Journal of General Internal Medicine. 2001;16(9):606-613.

58. Spielberger CD, Gorsuch RL, and , R.E. L. Manual for the State-Trait Anxiety Inventory. Palo Alto, CA: Consulting Psychologists Press; 1970.

59. Spielberger CD, Reheiser EC, Ritterband LM, Sydeman SJ, Unger KK. Assessment of Emotional States and Personality Traits: Measuring Psychological Vital Signs, Clinical Personality Assessment: Practical Approaches. In Butcher, J.N. (Ed.): New York: Oxford University Press; 1995.

60. Holm S. A simple sequentially rejective multiple test procedure. Scandinavian journal of statistics. 1979:65-70.

61. Bagby R, Taylor G. Affect dysregulation and alexithymia. Disorders of affect regulation: Alexithymia in medical and psychiatric illness. 1997:26-45.

62. Teten AL, Miller LA, Bailey SD, Dunn NJ, Kent TA. Empathic deficits and alexithymia in traumarelated impulsive aggression. Behavioral sciences \& the law. 2008;26(6):823-832.

63. Wood RL, Williams C, Kalyani T. The impact of alexithymia on somatization after traumatic brain injury. Brain Injury. 2009;23(7-8):649-654.

64. Wood RL, Williams C, Lewis R. Role of alexithymia in suicide ideation after traumatic brain injury. Journal of the International Neuropsychological Society. 2010;16(06):1108-1114.

65. Fakra E, Salgado-Pineda P, Delaveau P, Hariri AR, Blin O. Neural bases of different cognitive strategies for facial affect processing in schizophrenia. Schizophrenia Research. 2008;100(1-3):191205. 
66. Foland-Ross LC, Altshuler LL, Bookheimer SY, et al. Amygdala reactivity in healthy adults is correlated with prefrontal cortical thickness. The Journal of neuroscience. 2010;30(49):1667316678.

67. Hariri AR, Bookheimer SY, Mazziotta JC. Modulating emotional responses: effects of a neocortical network on the limbic system. Neuroreport. 2000;11(1):43.

68. Hariri AR, Tessitore A, Mattay VS, Fera F, Weinberger DR. The amygdala response to emotional stimuli: a comparison of faces and scenes. Neuroimage. 2002;17(1):317-323.

69. Cantor J, Ashman T, Dams-O'Connor K, et al. Evaluation of the short-term executive plus intervention for executive dysfunction after traumatic brain injury: a randomized controlled trial with minimization. Archives of physical medicine and rehabilitation. 2014;95(1):1-9. e3.

70. Levant RF, Halter MJ, Hayden EW, Williams CM. The efficacy of alexithymia reduction treatment: A pilot study. The Journal of Men's Studies. 2009;17(1):75-84.

71. Prince L, Ford C. Can alexithymia be improved? A case study. Poster presented at 9th Conference of the Neuropsychological Rehabilitation Special Interest Group of the World Federation for NeuroRehabilitation; July 2012; Bergan, Norway. 